
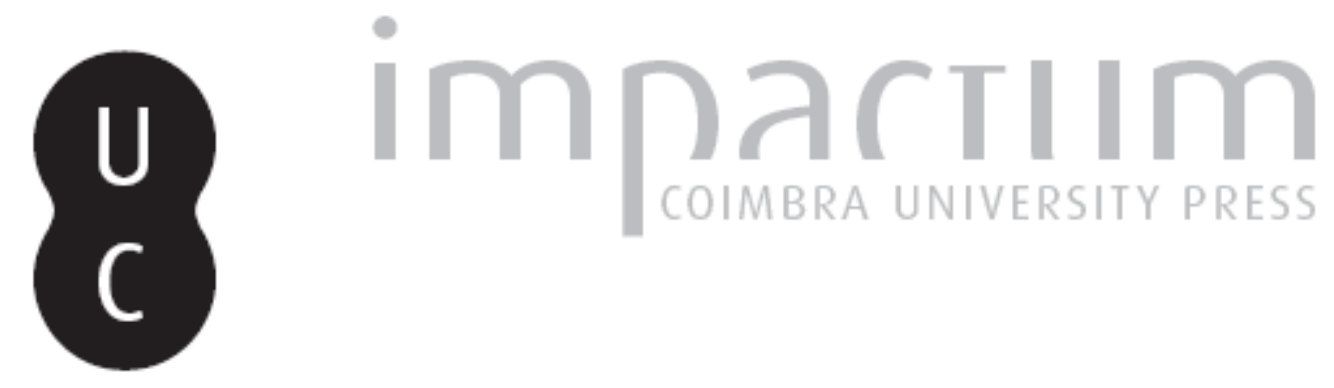

\title{
[Recensão a] Problemas de historiografia portuguesa nos séculos XX e XXI - a propósito do livro de António de Oliveira, Antiquarismo e História
}

\author{
Autor(es): $\quad$ Matos, Sérgio Campos \\ Publicado por: Centro de História da Sociedade e da Cultura \\ URL \\ persistente: \\ URI:http://hdl.handle.net/10316.2/39371 \\ DOI: \\ DOI:http://dx.doi.org/10.14195/1645-2259_14_13 \\ Accessed : $\quad$ 26-Apr-2023 14:16:23
}

A navegação consulta e descarregamento dos títulos inseridos nas Bibliotecas Digitais UC Digitalis, UC Pombalina e UC Impactum, pressupõem a aceitação plena e sem reservas dos Termos e Condições de Uso destas Bibliotecas Digitais, disponíveis em https://digitalis.uc.pt/pt-pt/termos.

Conforme exposto nos referidos Termos e Condições de Uso, o descarregamento de títulos de acesso restrito requer uma licença válida de autorização devendo o utilizador aceder ao(s) documento(s) a partir de um endereço de IP da instituição detentora da supramencionada licença.

Ao utilizador é apenas permitido o descarregamento para uso pessoal, pelo que o emprego do(s) título(s) descarregado(s) para outro fim, designadamente comercial, carece de autorização do respetivo autor ou editor da obra.

Na medida em que todas as obras da UC Digitalis se encontram protegidas pelo Código do Direito de Autor e Direitos Conexos e demais legislação aplicável, toda a cópia, parcial ou total, deste documento, nos casos em que é legalmente admitida, deverá conter ou fazer-se acompanhar por este aviso.

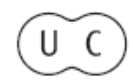




\section{4 \\ 2014}

\section{evista de História da Sociedade e da Cultura}

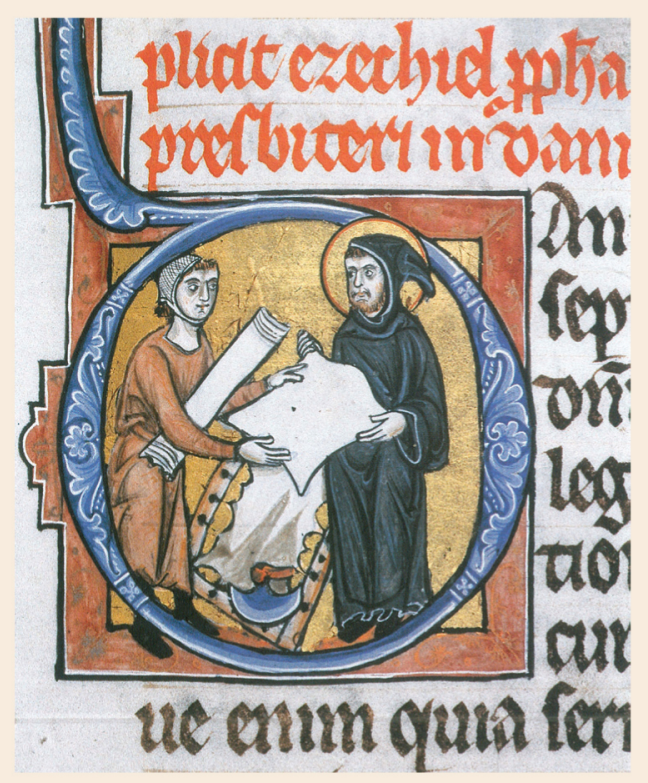

Centro de História da Sociedade e da Cultura Universidade de Coimbra 


\section{Recensões}

\section{Problemas de historiografia portuguesa nos séculos XX e XXI - a propósito do livro de António de Oliveira, Antiquarismo e História, Coimbra, Palimage, 2014}

António de Oliveira tem vindo a reunir em volume trabalhos publicados ao longo dos últimos decénios que bem testemunham a coerência de um exemplar percurso na historiografia portuguesa. As interrogações que a sua estimulante leitura suscita são afinal algumas das perplexidades com que os historiadores do nosso tempo se defrontam no seu trabalho e reflexão teórica. O meu propósito não é tanto o de recensear tão variado e enriquecedor conjunto de estudos, antes de reflectir acerca de problemas neles subjacentes.

Neste extenso volume, o Autor situa-se à partida no campo da história da historiografia - mesmo quando inclui também trabalhos sobre 1640 e diversas incursões no campo da história local, estabelecendo nexos com outras escalas, a nacional e a global. António de Oliveira é um historiador para quem o ofício não se situa fora do tempo, antes é dotado de uma historicidade que também ela se estuda. Cada geração e cada comunidade, num tempo específico, relacionam-se com o passado à sua maneira. François Hartog teorizou diferentes regimes de historicidade - diferentes modalidades de conviver com o passado, o presente e o futuro ${ }^{1}$. Estes diferentes modos podem sobrepor-se conviver em simultâneo. Na verdade, nem todos vivemos

1 François Hartog, Regimes d'historicité. Présentisme et experiences du temps, Paris, Seuil, 2003. 
no mesmo agora (por exemplo há quem em 2014 permaneça em 1920, não só nas atitudes em relação à vida, mas no que respeita ao vestuário, linguagem, etc.). Com as revoluções liberais de finais do século XVIII, o tempo passou a ser vivido por muitos como ruptura com a anterioridade, ter-se-á inaugurado uma consciência histórica voltada para o futuro, comandada por um ideal de progresso que aliás já vinha detrás. Também no campo historiográfico se exprimem intenções de ruptura e há continuidades. Lembre-se o caso de Herculano na sua crítica radical a uma história então ainda em voga, que qualificava de fabulosa, e recorria a mitos de fundação como o milagre de Ourique, as Cortes de Lamego ou à tradição que identificava os Portugueses com os Luistanos (na História de Portugal, em 1846). Ou, noutro contexto, e com objectivos bem diversos, no tempo da I República, a intenção do Integralismo Lusitano no sentido de rever sistematicamente a narrativa histórica liberal, considerada pessimista e desnacionalizadora. Quando o que se impunha para os adeptos do tradicionalismo era a construção de um novo cânone apologético da nação que identificava verdade e Tradição.

Ora em contraste com estes exemplos, uma das singularidades da obra do Prof. António de Oliveira (patente neste e noutros livros do autor) é precisamente o modo como num contínuo o historiador se relaciona com a historiografia que o antecede, com os seus antecessores. O modo como de um modo mais implícito do que explícito foi construindo a sua genealogia intelectual. Nessa relação, ao invés do que sucede com outros historiadores do nosso tempo (mas não da sua geração), caso de Vitorino Magalhães Godinho ou, mais recentemente, de António Hespanha - não há propriamente corte com o passado, antes um processo contínuo e cumulativo de diálogo e superação. Num notável estudo datado de 1993 - "Problemática da história local" -, confessa António de Oliveira a dado passo que, "embora preze a coerência do sistema, não sou pelas rupturas. Aceitando as continuidades, tenho o gosto narrativo das origens".2. O historiador incorpora o legado de uma história positiva, documentalmente fundamentada, atenta ao pormenor. Mas ao mesmo tempo está muito atento às tendências historiográficas europeias e americanas recentes e a inovações que ele próprio incorpora.

2 António de Oliveira, Pedaços de história local, vol.I, Coimbra, Palimage/CHSC, 2002. p. 21. 
António de Oliveira relaciona antiquarismo e história - história da mais actual e actualizada com notas bibliográficas da maior utilidade para o leitor, pois abrem janelas para que possa profundar novos horizontes que o autor percorreu. Não raro, as suas páginas enchem-se de extensas notas eruditas em excursos que nos transportam para novos caminhos. História que não apaga as melhores marcas do antiquarismo, atrevo-me a sugerir. Estimulante me parece justamente o modo como o autor dialoga com a diferença. E esta característica está presente no próprio título do livro.

Outra característica da historiografia de António de Oliveira é o recurso a metáforas que remetem para o campo da arte, do património (antiquarismo, pórtico...) e, noutro campo, para o trabalho agrícola braçal. Não por acaso a imagem seleccionada para a capa é um quadro de Silva Porto, Colheita - ceifeiras, que nos transporta para um tempo anterior à modernidade nos campos. Reproduz um óleo sobre tela naturalista e nela se vêm duas ceifeiras num campo mediterrânico a perder de vista. O próprio Autor esclarece, "muitas outras circunstâncias [no livro] evocam a colheita, a ceifa e os restolhos ao longo do volume: a historiografia pela igualdade de géneros, a colheita de dados depois da invenção da problemática (...) que por vezes não custa menos suor do que a ceifa em plena natureza" (Antiquarismo $e$ história, p. 12-13). Subjacente está um ofício artesanal que envolve duro e prolongado trabalho. E ao contrário do que alguns ingenuamente poderão pensar, as ciências humanas também usam metáforas - a palavra, deve lembrar-se, significava na sua origem grega transporte. Transporte de sentido, claro. Inevitavelmente, também os historiadores usam metáforas que, por evzes, abrem horizontes para outros campos do saber, para outras disciplinas. E estas figuras de estilo podem ser objecto de atenção em história da historiografia.

Há neste livro dois pontos que devem ser notados à partida:

1. a permanente conversa interior e balanceada entre a necessidade da pesquisa alargada, aprofundada, ou seja de exigente fundamentação empírica e a absoluta necessidade da invenção da problemática que se prende com a imaginação. E que, como sugere o Autor, está do lado da "desordem, a inovadora" (p. 330). Do lado do sonho. Entre antiquarismo e história: entre o imenso cuidado erudito e a paixão da história. Ciência e arte. $\mathrm{O}$ que podemos exprimir nas seguintes 
interrogações: como conciliar a racionalidade que sempre preside ao trabalho crítico do historiador e a imaginação por vezes desordenada e criadora? Como convivem razão e paixão no trabalho historiográfico? Lembre-se que o problema também se pode levantar em relação ao trabalho poético. Autores como Fernando Pessoa ou, mais tarde Ruy Belo não deixaram de sobre ele reflectir.

2. António de Oliveira assume que o ofício do historiador é comprometido (engagé, dizem os franceses): "investigar em História é comprometer-se, é tomar posição: as obras históricas são sempre autobiográficas" (p. 360). Sem dúvida autobiográficas, quanto mais não seja na escolha dos temas que se estudam, ou nas interrogações que se formulam. Neste sentido, como sugere o Autor, "a história é vida", e "investigar é conviver, estar voltado para o mundo que nos rodeia e não atitude de autista" (p. 314), "um permanente interrogar a partir das inquietações existenciais do presente" (p. 12). Não surpreende pois que António de Oliveira retome a postura de um Lucien Febvre e as palavras de Benedetto Croce - a história como pensamento e acção - colhidas do título do célebre livro do mestre italiano. Estamos perante um conceito humanista de história, sensível às problemáticas do tempo presente (caso dos estudos de género), ao estudo do convívio entre povos que pode colocar os homens numa relação de tolerância com a alteridade. Mas o historiador está bem consciente de que em todas as sociedades há conflitos, não tivesse ele estudado em profundidade o Poder e oposição politica em Portugal no periodo filipino (1580-1640), Lisboa, Difel, 1991 e os Movimentos sociais e poder em Portugal no século XVII, Coimbra, IHES, 2002.

Há um lado solar na escrita da história de António de Oliveira. A escrita da história é diálogo com os vivos: "Investigar é conviver" com o tempo presente, diz o autor. Mas a história também envolve uma relação com os ausentes, um diálogo com os mortos, com os homens e mulheres do passado. Nesse sentido, como sugeria Michel de Certeau, "falar dos mortos é (...) negar a morte e desafiá-la" ${ }^{3}$. Então, acrescento eu, é como se o ofício e a vida do historiador se entretecessem entre dois mundos: um presente e o

\footnotetext{
3 Michel de Certeau, L'écriture de l'histoire, Paris, Gallimard, 1975, p. 74.
} 
outro ausente, que conhecemos de um modo mediatizado. Pergunto: em que medida se podem conciliar comprometimento com o presente e vigilância crítica em relação à marca das convicções ideológicas, dos projectos de futuro que inevitavelmente transportamos? Lembrando que a história envolve uma operação de distanciação crítica em relação ao objecto que estuda. E que há graus de distanciação.

Há neste livro visões panorâmicas de conjunto - as excelentes sínteses sobre Antiquarismo e história em Coimbra, a História na FLUC ou o poder local em tempo de globalização - estudos monográficos (1640), biografias intelectuais (por exemplo, a de António de Vasconcelos), evocações de historiadores já desparecidos (Salvador Dias Arnaut, Luís Ferrand de Almeida ou Sérgio da Cunha Soares), apresentações de problemáticas em prefácios de livros e monografias. Mas mesmo nos estudos dedicados a historiadores - caso de D. Francisco Manuel de Melo ou de António de Vasconcelos - a preocupação de entender o individual, traduz-se sempre na procura dos seus nexos com as tendências culturais do tempo em que se inscrevem. Assim, no tempo de D. Francisco Manuel de Melo, era com recurso à história que se poderia alcançar "a prudência, tão necessária à arte de reinar" (Luís Cabrera de Cordoba, citado na p. 52). Já no século XIX, a história servia a formação de cidadãos e os historiadores investiam-se de uma função social e de uma missão cívica. Na verdade, a história sempre foi instrumentalizada por interesses políticos e propagandas ideológicas as mais variadas. Exemplo excelente, convocado pelo autor é a restauração de 1640 (vd. p. 412-428). Mas a história também é, como acima frisei, distanciação crítica em relação ao seu objecto.

Destaquemos ainda quatro outras problemáticas que estão presentes ou emanam deste estimulante livro do Prof. António de Oliveira:

1. A atenção atribuída aos conceitos e à sua transformação, na consciência de que estes são indispensáveis na captação e compreensão sempre mais profunda da realidade histórica. Mas a vida é sempre mais complexa do que a ferramenta conceptual, como já Joaquim de Carvalho alertava. Considerem-se, por exemplo três conceitos: antiquário, antiquarismo, arqueologia. No princípio do século XVIII, o termo antiquário era definido como "curioso da antiguidade (como de palavras, papéis, de costume ou de medalhas antigas)" (Bluteau, 1712). 
Antiquarismo "andou associado (...) às actividades da arqueologia mesmo para lá do aparecimento desta palavra na língua portuguesa" (p. 114) - esclarece António de Oliveira. Ora arqueologia remete para "o conhecimento do que é antigo, ou melhor da antiguidade" (p. 115), foi entendida como "ciência das antiguidades" (p. 116). E houve quem se referisse a "antiguidades literárias" (Teixeira de Carvalho, 1915). O seu conceito mudaria muito até aos dias de hoje - refira-se o seu uso num sentido bem diverso por Michel Foucault em L'Archéologie du savoir (1969) que incide nas múltiplas camadas do saber e modos diversos de aceder ao não evidente na ordem dos discursos. Por outro lado, no séc. XIX operara-se a distinção entre antiquário e historiador - já com Niebhur. E Nietzsche tinha um olhar muito crítico sobre a história antiquária ${ }^{4}$. $\mathrm{O}$ antiquário ficava preso ao pormenor erudito sem alcançar a síntese e o antiquarismo tornava-se uma história sem pensamento como sugeriu Geoffrey Elton (citado pelo Autor). Mas houve historiadores de grande valor, qualificados de antiquários ainda no séc. XIX: caso de João Pedro Ribeiro, em quem Herculano reconheceu um mestre. Exemplos que mostram bem a complexidade dos problemas conceptuais e como o vocabulário, quando usado de um modo descuidado, pode ser redutor. Donde, é saudável submeter rótulos apressados ao crivo da crítica.

2. objectividade e o cuidado no apuramento dos factos. A dado passo, o Autor cita Joaquim de Carvalho: "sem a caça paciente e lúcida dos factos todas as construções serão frágeis e precárias” (p. 235-236). António de Oliveira é herdeiro dessa tradição de história-ciência fortemente enraizada na Faculdade de Letras de Coimbra. Nela dominava o "império da objectividade" a que também Joaquim de Carvalho se referia e que o autor de Antiquarismo e história filia no historicismo alemão - como lembra, "pelo menos desde 1923", estabeleceram-se relações estreitas entre a Universidade de Coimbra e várias universidades alemãs. Mas António de Oliveira também é herdeiro do movimento dos Annales, que renovaram profundamente

4 F. Nietzsche, Untimely Meditations (Ed. D.Breazeale), Cambridge, Cambridge University Press, 1997 (1874), p. 74-75. 
a historiografia francesa, e depois europeia no séc.XX, desde 1929. E que foram uma referência para historiadores que escrevem na Revista Portuguesa de História (publicada a partir de 1941) - caso de Torquato de Sousa Soares, certamente um dos primeiros a divulgar Marc Bloch em Portugal - e para os então jovens historiadores que passaram pela Faculdade de Letras de Lisboa: Vitorino Magalhães Godinho, António José Saraiva, Jorge Borges de Macedo, Joel Serrão, Joaquim Barradas de Carvalho, entre outros.

Mas o que entende o historiador por objectividade? Objectividade implica "considerar os outros como diferentes de nós e não como corrente de intersubjectividade projectada que os torna idênticos" (p. 318). Ensinamento da maior valia, num tempo em que é moda transportar para o passado o juízo de valor fácil, e em que prolifera a adjectivação. O que António de Oliveira sugere é que objectividade envolve o respeito pela autonomia do objecto. Daí que cite em nota Karl Popper: "O que se denomina objectividade científica consiste tão-só na abordagem crítica (...). É a disponiblidade para a crítica mútua que constitui a objectividade" (p. 261, em $O$ mito do contexto, p. 159). A história é pois entendida pelo autor como esforço de aproximação de uma possível objectividade. Mas não deixa de estar atento à a micro-história, à história global, sem esquecer as tendências ditas pós-modernistas, a erosão das grandes narrativas e o relativismo - a meu ver excessivo - em que por vezes se incorreu ao aceitar acriticamente as perspectivas teóricas de Hayden White ou Paul Veyne (vd. p. 459 e ss) que, todavia, tanto contribuiram para relançar o debate acerca do estatuto da história, a partir dos anos 80 .

Há muito que o historiador se interessa pela história local - e tem produzido obra marcante também neste campo. Mais recentemente tem-se interessado pela relação entre três escalas: a local, a nacional e a transnacional ou global. Há em Portugal uma tradição de história local que vem do século XVIII, das academias, e que passou depois para a Universidade. E foi aliás incentivada pelo poder político central como instrumento de conhecimento do país real e dos seus recursos e pela Igreja desde meados do século XVIII (vejam-se as portarias de 1847 e de 1854 e lembre-se que a história das dioceses era obrigatória nos seminários desde 1845) (p. 447, n. 32). O tópico nação - referente identitário marcante na cultura política da modernidade - 
dominou durante os dois últimos séculos. Mas os processos de transformação social, tecnológica e cultural que se prendem com a globalização impõem uma realidade cada vez mais evidente: a de que somos todos translocais. Donde, nota António de Oliveira, “o conhecimento é total, mas é também local” (p. 466). Há heterogeneidade na escala individual, local, e na escala nacional. Mas na hipermodernidade de que fala Lipovetsky também há o rolo compressor da homogeneidade, de uma cultura global sem limites que se impõe nos grandes meios de comunicação e nos "não lugares" (Marc Augé), por exemplo.

3. Outra questão a que se refere o Autor é o da relação entre história e literatura e o lugar do romance histórico (p. 177 e ss.), prestando atenção aos autores que cultivaram simultaneamente literatura e história. Herculano chegou a escrever que há mais história no romance histórico "do que nos grandes e inteiriços escritos dos historiadores" (p. 187). O que, a meu ver, levanta ainda hoje uma problemática do maior interesse acerca das possibilidades e limites entre história e ficção. Será que, como pretendia Herculano em 1843, o romancista consegue mais eficazmente penetrar na psicologia íntima das personalidades já desaparecidas? Questão perminente num tempo de aceleração da experiência histórica como o nosso, em que não raro as pessoas são reduzidas a estatísticas e a projecções imediatistas. E em que, talvez por isso mesmo, o romance histórico tem tanta aceitação. Sublinhe-se, por último, a motivação do historiador em estar atento à relação entre a história e as outras ciências humanas: linguística e estudos literários, claro, mas também, antropologia, sociologia, economia.

Concluindo: como poderiamos hoje conceber um conceito de antiquarismo? Gosto erudito pelos vestígios do passado? Tempo em que dominava a pesquisa documental erudita desligada de preocupações teóricas? Mas, por exemplo, não serão o inventário, descrição e classificação de ruínas indispensável para o seu estudo - seja em que perspectiva for -, sempre conceptualmente marcados? Nesse caso poderíamos traçar um itinerário que vai do antiquarismo à história dos nossos dias, mas incorporando nesta o antiquarismo como parece sugerir o Autor? Prefiro antes, como sugere subliminarmente o Professor António de Oliveira, estabelecer uma relação contínua entre antiquarismo e história. E assim articulá-lo com um conceito humanista de história, aberto à diferença e ao diálogo com outros tempos, 
lugares e pessoas. Um conceito que, embora não explícito, se me afigura subjacente à escrita da história do autor.

Sérgio Campos Matos

sergiocamposmatos@gmail.com

Universidade de Lisboa, Centro de História

Silva, Maria João Oliveira e - A escrita na Catedral. A chancelaria episcopal do Porto na Idade Média, edição: Centro de Estudos de História Religiosa; co-edição Centro de Investigação transdisciplinar "Cultura, Espaço e Memória”. Prefácio de Maria Josefa Fuentes, Lisboa, 2013, 398 págs.

Maria João Oliveira e Silva é investigadora e bolseira de pós-doutoramento da Fundação para a Ciência e Tecnologia, tendo realizado a sua carreira académica na Escola da cidade que a viu nascer - a Faculdade de Letras da Universidade do Porto. Aqui, obteve os três graus do Ensino Superior: Licenciatura, Mestrado e Doutoramento em História. Apesar de muito jovem, tem revelado possuir dotes notáveis, na área, em especial, das Ciências da Paleografia e da Diplomática, reforçados, diga-se, por uma assinalável cultura humanística, uma inteligência fina e um bom domínio da palavra escrita.

A obra em epígrafe corresponde à tese de doutoramento, orientada pela minha Estimada Colega Doutora Cristina Cunha, e por mim própria que, então, aceitei o seu amável convite.

Maria João Oliveira e Silva, entusiasmada e apaixonada pelo estudo da Sé do Porto, concretizado na dissertação de Mestrado, hoje livro, intitulada Scriptores et notatores. A produção documental da Sé do Porto (1113-1247) [Edição da Fio da Palavra, 2008], deu continuidade a esta inesgotável linha de investigação. É a autora quem, na Introdução, escreve: "queremos continuar o trabalho desenvolvido na Dissertação de Mestrado". Com efeito, mantendo-se "dentro" da instituição eclesiástica em apreço, avançou no tempo mais de um século e meio, ou seja, estabeleceu como termo ad quem o ano de 1406, data que marcou a transferência do senhorio episcopal da cidade para o Rei. 